\title{
Local cerebral glucose utilisation in treated and untreated patients with Parkinson's disease*
}

\author{
D ROUGEMONT,$\uparrow \mathrm{JC}$ BARON,$\uparrow \mathrm{P}$ COLLARD,$\uparrow \mathrm{P}$ BUSTANY, $\uparrow \mathrm{D}$ COMAR,$\uparrow \mathrm{Y}$ AGID $\ddagger$
}

From the Service Hospitalier Frédéric Joliot CEA, Département de Biologie, Orsay, $\dagger$ and the Clinique de Neurologie et de Neuropsychologie Hôpital de la Salpétrière Paris, $¥$ France

SUMMARY Using the ${ }^{18}$ f-fluoro-2-deoxy-d-glucose technique and positron emission tomography (PET), the local cerebral glucose utilisation (1CMRGlc) was measured in four non-demented patients with early-onset, bilateral Parkinson's disease characterised by the predominance of akinesia. The study was done twice, first in the untreated condition, and then after levodopa had been resumed. Despite a marked clinical improvement, we found no alteration in ICMRGlc between the first and second studies in any of the brain structure analysed. Compared to control values, ICMRGIc in the basal ganglia was moderately increased in both studies. These essentially negative findings agree with most previous human or animal studies, and indicate that the functional alterations in the central dopaminergic systems of patients with Parkinson's disease have metabolic correlates that are too small to be demonstrated by current PET devices.

The typical symptomatic triad of Parkinson's disease, that is akinesia, rigidity, and tremor, implies that functional alterations take place in certain cerebral structures. Since energy metabolism in the brain has been shown to be coupled to function,' changes in regional energy metabolism specific to the functional abnormalities of Parkinson's disease might be expected to occur. Such changes should be found in the structures deprived of their normal dopaminergic afferences, principally the striatum ${ }^{2}$ and the cortico-limbic areas ${ }^{3}$ and, as a secondary effect, in the structures receiving projections from these structures.

In the attempt to use local energy metabolism as a marker of disordered dopaminergic transmission systems, several studies of the local cerebral glucose utilisation (ICMRGlc) using ${ }^{14} \mathrm{C}$-2-deoxy-D-glucose $\left({ }^{14} \mathrm{CDG}\right)$ autoradiography in rats with unilateral destruction of the dopaminergic systems have failed to show any consistent pattern of changes, ${ }^{4-9}$ although some reported striking alterations. ${ }^{45}$ Human studies of Parkinson's disease patients have been, for methodological reasons, restricted to 2-dimensional ${ }^{133}$ xenon regional cerebral blood flow (rCBF) $)^{10-12}$ or

Address for reprint requests: JC Baron, MD, Service Hospitalier Frédéric Joliot, 91406 Orsay, France.

*Presented in part at the XIth International Symposium on Cerebral Blood Flow and Metabolism, Paris, France, 20-24 June 1983.

Received 26 August 1983 and in revised form 9 January 1984. Accepted 10 January 1984 oxygen- $15^{13}$ investigations, but again have provided discrepant results.

Because it allows non-invasive 3-dimensional quantitative measurement of ICMRGlc in humans, positron emission tomography (PET) was used in the present work to investigate further this issue. Our protocol was essentially designed to see whether, in a small series of levodopa responders acting as their own controls, levodopa therapy would have any discernible effect on ICMRGlc.

\section{Patients}

Four severely affected non-demented male patients volunteered for the study (table 1). They were asked to participate in the investigation because of expected severe degeneration of central dopaminergic systems as suggested by: early onset of the disease, marked severity of akinesia with varying degree of rigidity and tremor, excellent response to levodopa therapy, and early occurrence of levodopa-induced adverse reactions such as on-off phenomena and abnormal involuntary movements. Each patient underwent in the fasting state two PET studies, the first $\mathbf{4 8}$ hours after all treatment had been stopped, and the second the next day, after treatment had been resumed for about 22 hours. In order to ensure reproducibility, repositioning of the patient's head under the field of the positron camera was as accurate as possible, using laser beams projected on external landmarks on the forehead. Just prior to each study, a Parkinson's disease clinical score was obtained, ${ }^{14}$ grading the severity of the symptoms so that the more severe the symptoms the higher the grade. 
Table 1 Clinical data

\begin{tabular}{|c|c|c|c|c|c|}
\hline Patient & Sex & Age (yr) & $\begin{array}{l}\text { Age at onset of } \\
\text { disease (yr) }\end{array}$ & $\begin{array}{l}\text { Clinical } \\
\text { stage }\end{array}$ & Treatment (mg/day) \\
\hline 1 & $\mathbf{M}$ & 54 & 40 & 4 & $\begin{array}{l}\text { Levodopa } 600 \mathrm{mg} \text {, Benserazide } 150 \mathrm{mg} \text {, } \\
\text { Trihexyphenidile } 9 \mathrm{mg}\end{array}$ \\
\hline 2 & $\mathbf{M}$ & 51 & 43 & 4 & $\begin{array}{l}\text { Levodopa } 150 \mathrm{mg} \text {, Benserazide } 37.5 \mathrm{mg} \text {, } \\
\text { Bromocriptine } 45 \mathrm{mg}\end{array}$ \\
\hline 3 & $\mathbf{M}$ & 53 & 46 & 3 & $\begin{array}{l}\text { Levodopa } 500 \mathrm{mg} \text {, Benserazide } 125 \mathrm{mg} \text {, } \\
\text { Domperidone } 15 \mathrm{mg} \text {, Trihexyphenidile } 6 \mathrm{mg} \text {, } \\
\text { Bromocriptine } 9 \mathrm{mg}\end{array}$ \\
\hline 4 & $\mathbf{M}$ & 54 & 43 & 3 & $\begin{array}{l}\text { Levodopa } 600 \mathrm{mg} \text {, Benserazide } 150 \mathrm{mg} \text {, } \\
\text { Pergolide mesylate } 4 \mathrm{mg}\end{array}$ \\
\hline
\end{tabular}

*From Hoehn and Yahr ${ }^{32}$

\section{Methods}

We used the ${ }^{18}$ f-fluoro-2-deoxy-d-glucose $\left({ }^{18} \mathrm{FDG}\right)$ method to measure 1CMRGIc ${ }^{15-16}$, as applied to PET, ${ }^{16}{ }^{17}$ using the ECAT II single slice positron tomograph, ${ }^{18}$ the resolution of which is $\sim 16 \mathrm{~mm}$ in the lateral plane and $\sim 19 \mathrm{~mm}$ in the axial one (slice thickness), with medium resolution filter. The studies were performed in dim light, and the environment was kept as silent as possible (except for the sound of moving gantry of the detectors); the patient was asked to keep the eyes closed and not to move.

After iv injection (over about 20 seconds) of ${ }^{18}$ FDG (3-6 $\mathrm{mCi})$, blood samples were collected using the time-frame advocated by Phelps et al, ${ }^{16}$ and the heated-hand vein procedure was employed to obtain arterialised blood while avoiding arterial catheterisation. ${ }^{16}$ Injection of ${ }^{18} \mathrm{FDG}$ was started only after proper arterialisation of venous blood was achieved, by comparing its oxygen content to that of arterial blood (single femoral puncture). The samples were immediately put on ice, and subsequently centrifuged to measure the ${ }^{18} \mathrm{~F}$ plasma concentrations in a well-counter calibrated for ${ }^{18} \mathrm{~F}$ and cross-calibrated with the ECAT system to ensure proper quantitation of ICMRGlc. ${ }^{19}$ Five samples were also used to measure the plasma glucose content, and the average value $(\mathrm{CP})$ was used thereafter.

Two different approaches were carried out simultaneously to measure ICMRGIc. One approach was the classic in vivo autoradiographic paradigm, ${ }^{15} 16$ which uses the ${ }^{18} \mathrm{FDG}$ blood history $\left(\mathrm{Cp}^{*}\right), \mathrm{Cp}$ and the regional tissue ${ }^{18} \mathrm{~F}$ concentration $\left(C^{*} t\right)$ determined in the PET quantitative images obtained at times $>45$ min after iv injection. In this approach, we used the operational equation of Huang $e t-$ $a l,{ }^{17}$ which includes the 4 FDG rate-constants (that is, $k^{*}$, to $\mathrm{k}^{*}$ ) measured by these authors in young healthy adults, and the lumped constant ( $\mathrm{LC}=0.42$ ) derived empirically from the same studies. ${ }^{17}$ To do this, PET images of three contiguous head levels $(O M+1.5 \mathrm{~cm}, O M+3.5 \mathrm{~cm}, O M$ $+5.5 \mathrm{~cm}$ ) parallel to the OM Line were obtained in each study at times $>55 \mathrm{~min}$, with routine care for accurate quantitation being taken, ${ }^{19}$ and were subsequently transformed pixel by pixel into quantitative ICMRGlc images. In this approach, however, the assumption is made that the real $k^{*}$ values of our Parkinson's disease patients do not deviate much from the standard $k^{*}$ values used in the autoradiographic operational equation. It has been shown ${ }^{20}$ that inaccurate ICMRGIc may obtain if this assumption is not true. We therefore chose to measure regionally the real $k^{*}$ values and hence the "true" ICMRGlc in our Parkinson's disease studies, using the method originally described for ${ }^{14} \mathrm{CDG}$ in rats by Sokoloff et al,,$^{21}$ and subsequently applied to human PET studies by Huang et al ${ }^{17}$ and Reivich et al. ${ }^{22}$ To apply this so-called "kinetic" approach, both the $\mathrm{Cp}^{*}$ curve and the ${ }^{18} \mathrm{~F}$ regional cerebral accumulation curves (decay-corrected) are needed. The latter were obtained by scanning repeatedly the midcut (basal-ganglia) level from time of injection to $t=56 \mathrm{~min}$; this was a 12scan sequence with mid-scan times of $0 \cdot 5,1 \cdot 7,2 \cdot 9,4 \cdot 2,5 \cdot 4$, $6.7,9.0,12.5,18.9,29.6,42.4$ and $56.2 \mathrm{~min}$. (The rapid initial sampling was carried out to allow a better determination of $k^{*}{ }_{1}$ ) Subsequently, the ${ }^{18} \mathrm{~F}$ accumulation curve in each selected region of interest (see below) was fitted, using an original mathematical iterative algorithm, ${ }^{23}$ to a 3 exponential model, thus allowing to measure regionally each of the $3 k^{*}$ values (that is, $k^{*}$ to $k^{*}, k_{3}^{*}$ being ignored in this relatively short scanning time ${ }^{22}$ ). With the set of measured $k$ * values, the "true" ICMRGlc was computed using the equation ICMRGlc $=|\mathrm{Cp} / \mathrm{Lc}| .\left|\mathbf{k}^{*}{ }_{1} . \mathrm{k}^{*}{ }_{3}\right|$ $\mathrm{k}_{2}{ }_{2}+\mathrm{k}_{3}{ }_{3} \mid$ proposed by Huang et al, ${ }^{17}$ where $\mathrm{LC}=0.42$. One potential inaccuracy in the kinetic method results from the presence of significant amounts of intra-vascular ${ }^{18} \mathrm{FDG}$ in the initial PET scans. To avoid the increase of both dosimetry and examination time of an additional cerebral blood volume PET scan, we devised a standardised, time variable percent correction of the elementry ${ }^{18} \mathrm{~F}$ tissue curves for vascular ${ }^{18} \mathrm{~F}$ activity (using published da$\left.\operatorname{ta}^{16}\right)$, a correction which should be quite acceptable for the present purposes. Generally, excellent fitting of the corrected ${ }^{18} \mathrm{~F}$ curves was achieved within $20-30$ iterations. Occasionally, however, statistical fluctuations due to low count-rates in the initial ${ }^{18}$ FDG scans induced slower convergence and/or less optimal fit. Nevertheless, the final ICMRGlc value depended very little on the exact individual fitting values, a fact previously stressed by Huang et al. ${ }^{17}$

To investigate the validity of our kinetic method, we compared the 1CMRGlc values (expressed in $\mathrm{mg} \mathrm{Gld} / 100 \mathrm{~g} /$ min) obtained by both approaches in various cerebral structures of seven controls (mean age 57 yrs) (table 2). As expected the kinetic values were $\sim 20 \%$ lower than the autoradiographic values, an effect of using the $k^{*}$. FDG constant in the latter paradigm but not in the former. ${ }^{17} 22$ Nevertheless, the regional pattern of CMRGlc was identical in both studies (correlation coefficient $r=0.979$, kinetic $\mathrm{CMRGlc}=0.815$, autoradiographic CMRGlc + 
Table 2 Mean ( $\pm S D$ ) CMRGlc values obtained by both methodological approaches in various brain structures in 7 control subjects, as well as the FDG rate constants $\left(k_{1}^{*} k^{*}{ }_{2}\right.$ and $\left.k_{3}^{*}\right)$ measured by the kinetic approach in these structures.

\begin{tabular}{|c|c|c|c|c|c|}
\hline & $\begin{array}{l}\text { CMRGlc } \\
\text { autoradiographic } \\
\text { mg/100 g/min }\end{array}$ & $\begin{array}{l}\text { CMRGlc } \\
\text { kinetic } \\
\text { mg/100 g/min }\end{array}$ & $k^{*} \min ^{-1}$ & $k^{*}{ }_{2} \min ^{-1}$ & $k^{*}{ }_{3} \min ^{-1}$ \\
\hline
\end{tabular}

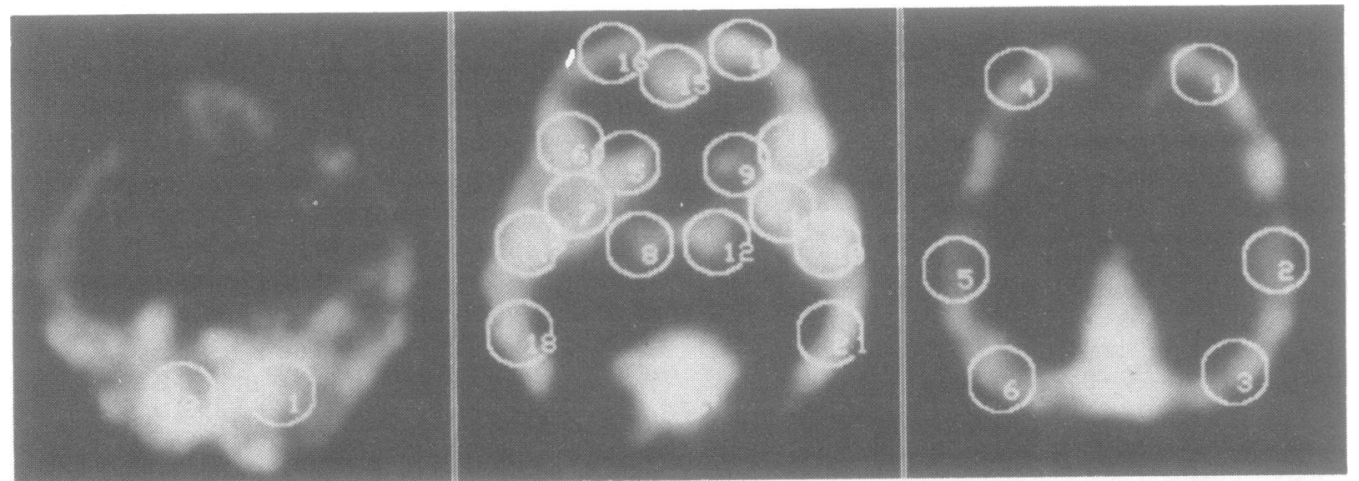

Fig. 1 Analysis of regional CMRGlc by means of several regions of interest (ROIs), placed on the three head levels studied parallel to the $O M$ line (from left to right, $O M+1.5 \mathrm{~cm}, O M+3.5 \mathrm{~cm}, O M+5.5 \mathrm{~cm}$ ). Circular $R O I s$ were first placed on the right hemisphere and then mirror-copied over the left side with reference to a vertical axis; medially-positioned ROIs were also used. They were placed on the cerebellum (plane 1); the head of caudate nucleus (ROIs 5 and 9), the lenticular nucleus (7 and 11), the thalamus (8 and 12), the medial (15) and lateral frontal (16 and 19) cortex, the occipito-visual cortex (14), and the temporal cortex (remaining ROIs) on plane 2; and the superior frontal (1 and 4) and parietal (remaining ROIs) cortex on plane 3. Since only the basal-ganglia level (plane 2) could be subjected to a kinetic analysis, only the corresponding ROIs provided "kinetic" 1CMRGIc data; because potentially affected by the large vascular space of the superior sagittal and straight sinuses, the occipito-visual area (14) was analysed only with the autoradiographic method.

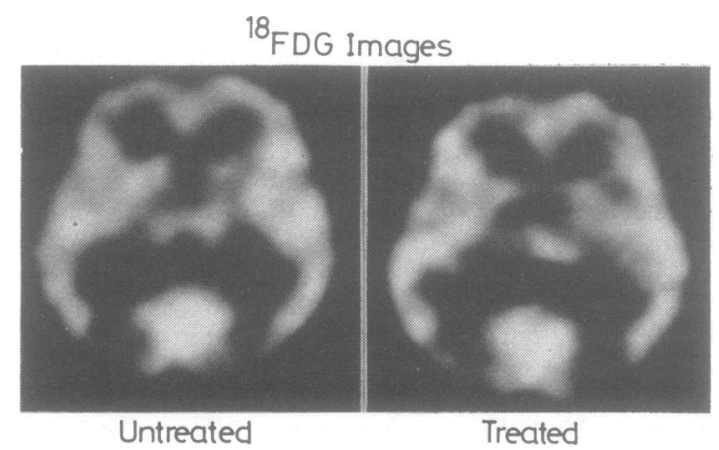

Fig. 2 Autoradiographic CMRGlc images at the basal-ganglia level obtained in patient 2 in the untreated (left) and treated (right) conditions. Whiter shades of gray indicate higher metabolic rate. Left hemisphere is shown on left side of each image. The regional metabolic pattern appears essentially unchanged despite clinical improvement, and does not differ from that seen in control subjects.
0.002). Furthermore, the rate constants $k_{2}{ }_{2}$ and $k^{*}{ }_{3}$ found in our controls closely agree with those reported by Phelps et al,,$^{16}$ although $\mathrm{k}_{3}$ was moderately lower in our study presumably because these authors ${ }^{16}$ introduced a dephosphorylation rate constant $\left(\mathrm{k}^{*}\right)$ in their curve fitting algorithm.

On the whole, therefore, each study yielded autoradiographic ICMRGlc images of the three head-levels, and kinetic ICMRGlc data of the basal-ganglia level only.

Data analysis Using a standardised protocol, ${ }^{24}$ regional CMRGlc values were obtained in circular $\left(4 \mathrm{~cm}^{2}\right)$ regions of interest (ROIs) placed symmetrically in the caudate (head), lenticular and thalamic nuclei, and in the cerebellar, temporal, parietal, occipito-visual, medial-frontal and lateral frontal cortex (see fig 1). It is recognised that the anatomical positioning of the ROIs, which followed the ${ }^{18} \mathrm{FDG}$ atlas of Mazziotta et al, ${ }^{25}$ remained only approximate. 
Table 3

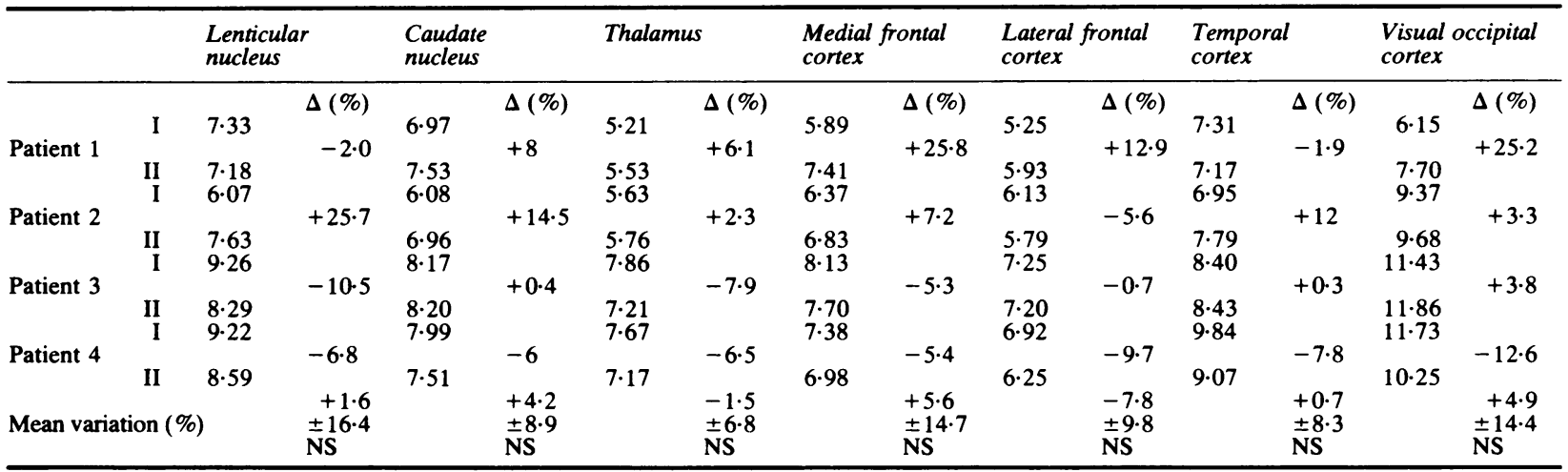

Values given are local autoradiographic CMRGlc values; $\Delta(\%)$ is the percent difference in local CMRGlc between study I (untreated) and Study II (treated); NS = no significant difference (paired t-test).

Table 4

\begin{tabular}{|c|c|c|c|c|c|c|c|c|c|c|}
\hline & $\begin{array}{l}\text { Clinical } \\
\text { score }\end{array}$ & & $\begin{array}{l}\text { Lenticular } \\
\text { nucleus }\end{array}$ & $\begin{array}{l}\text { Caudate } \\
\text { nucleus }\end{array}$ & Thalamus & $\begin{array}{l}\text { Medial } \\
\text { frontal } \\
\text { cortex }\end{array}$ & $\begin{array}{l}\text { Lateral } \\
\text { frontal } \\
\text { cortex }\end{array}$ & $\begin{array}{l}\text { Temporal } \\
\text { cortex }\end{array}$ & $\begin{array}{l}\text { Parietal } \\
\text { cortex }\end{array}$ & $\begin{array}{l}\text { Visual } \\
\text { occipital } \\
\text { cortex }\end{array}$ \\
\hline \multirow{2}{*}{ Controls $(n=7)$} & \multirow{2}{*}{0} & & $6.92 \pm 0.49$ & $6.43 \pm 0.67$ & $5.67 \pm 0.81$ & $7 \cdot 11 \pm 0.84$ & $6.02 \pm 0.57$ & $7 \cdot 0 \pm 0.78$ & $7.64 \pm 0.64$ & $8 \cdot 41 \pm 1 \cdot 11$ \\
\hline & & & $\begin{array}{l}5.67 \pm 0.37 \\
7.97 \pm 1.55\end{array}$ & $\begin{array}{l}5.40 \pm 0.44 \\
7.30 \pm 0.97\end{array}$ & $\begin{array}{l}4.73 \pm 0.58 \\
6.54 \pm 1.42\end{array}$ & $\begin{array}{l}5.79 \pm 0.65 \\
6.94 \pm 1.0\end{array}$ & $\begin{array}{l}5.15 \pm 0.47 \\
6.39 \pm 0.89\end{array}$ & $\begin{array}{l}5.85 \pm 0.52 \\
8.12 \pm 1.30\end{array}$ & $\overline{7.44} \pm 1.89$ & $\begin{array}{l}6 \cdot 57 \pm 0.84 \\
9 \cdot 67 \pm 2 \cdot 57\end{array}$ \\
\hline \multirow{2}{*}{$\begin{array}{l}\text { Study I } \\
\text { Patients }(n=4)\end{array}$} & 31 & & $6.58 \pm 0.98^{*}$ & $6.06 \pm 0.71$ & $5.55 \pm 0.65$ & $5.86 \pm 0.48$ & $5.55 \pm 0.33$ & $6.73 \pm 0.70^{*}$ & - & - \\
\hline & & $7.92 \pm 0.64 \dagger$ & $7 \cdot 55 \pm 0.51 \ddagger$ & $6.42 \pm 0.90$ & $7 \cdot 23 \pm 0.40$ & $6.29 \pm 0.63$ & $8.12 \pm 0.82$ & $8.74 \pm 0.87$ & $9 \cdot 87 \pm 1 \cdot 72$ \\
\hline Comparison IV/I & & & $\begin{array}{l}6 \cdot 18 \pm 0.58 \\
\text { NS }\end{array}$ & $\begin{array}{l}6.01 \pm 0.37 \\
\text { NS }\end{array}$ & $\begin{array}{l}5.39 \pm 1.05 \\
\text { NS }\end{array}$ & $\begin{array}{l}6 \cdot 0 \pm 0 \cdot 85 \\
\text { NS }\end{array}$ & $\begin{array}{l}5.36 \pm 0.77 \\
\text { NS }\end{array}$ & $\begin{array}{l}6.30 \pm 0.77 \\
\text { NS }\end{array}$ & $\overline{\mathrm{NS}}$ & $\overline{\text { NS }}$ \\
\hline
\end{tabular}

Mean and one SD of local CMRGlc values in 7 controls and 4 patients with Parkinson's Disease studied in the untreated (study I) and treated state (Study II). Subtypes a and b mean CMRGlc values obtained by the autoradiographic and the kinetic approach, respectively; NS = no significant variation between Study I and Study II.

* $p<0-05$

tp $<0.01$

$\neq \mathrm{p}<0.001$, with respect to controls.

\section{Results}

Visual inspection of the CMRGlc autoradiographic images did not disclose any conspicuous difference between controls and Parkinson's disease patients, or between the untreated and treated state in any Parkinson's disease patient (fig 2). Significant rightleft asymmetry in lCMRGlc was not observed in any Parkinson's disease patient.

Despite a dramatic clinical improvement from first to second study (mean Parkinson's disease scores 35 and 18 , respectively), we found no significant change in ICMRGlc (both methodological approaches) in any brain area analysed (table 3 ). As found in controls, and for reasons explained above, the "kinetic" method yielded ICMRGlc values about $15 \%$ lower than corresponding "autoradiographic" values.

Compared to ICMRGlc values from controls of roughly similar age, the kinetic lCMRGlc values of lenticular and temporal areas of first study were found significantly higher $(p<0.05)$, and the autoradiographic ICMRGlc values of caudate and lenticular areas of second study were found significantly higher $(p<0.01$ and $p<0.001$, respectively) (table 4 , fig 3 ).

\section{Discussion}

Interpretation of the increases in ICMRGlc found in Parkinson's disease patients relative to controls (table 4, fig 3 ) is complicated by the fact that the two methodological approaches used for measuring ICMRGlc provided discrepant results. In the untreated state, only the kinetic values in the lenticular nucleus and temporal cortex were significantly higher than controls; in the treated state, on the other hand, only the autoradiographic values of the 


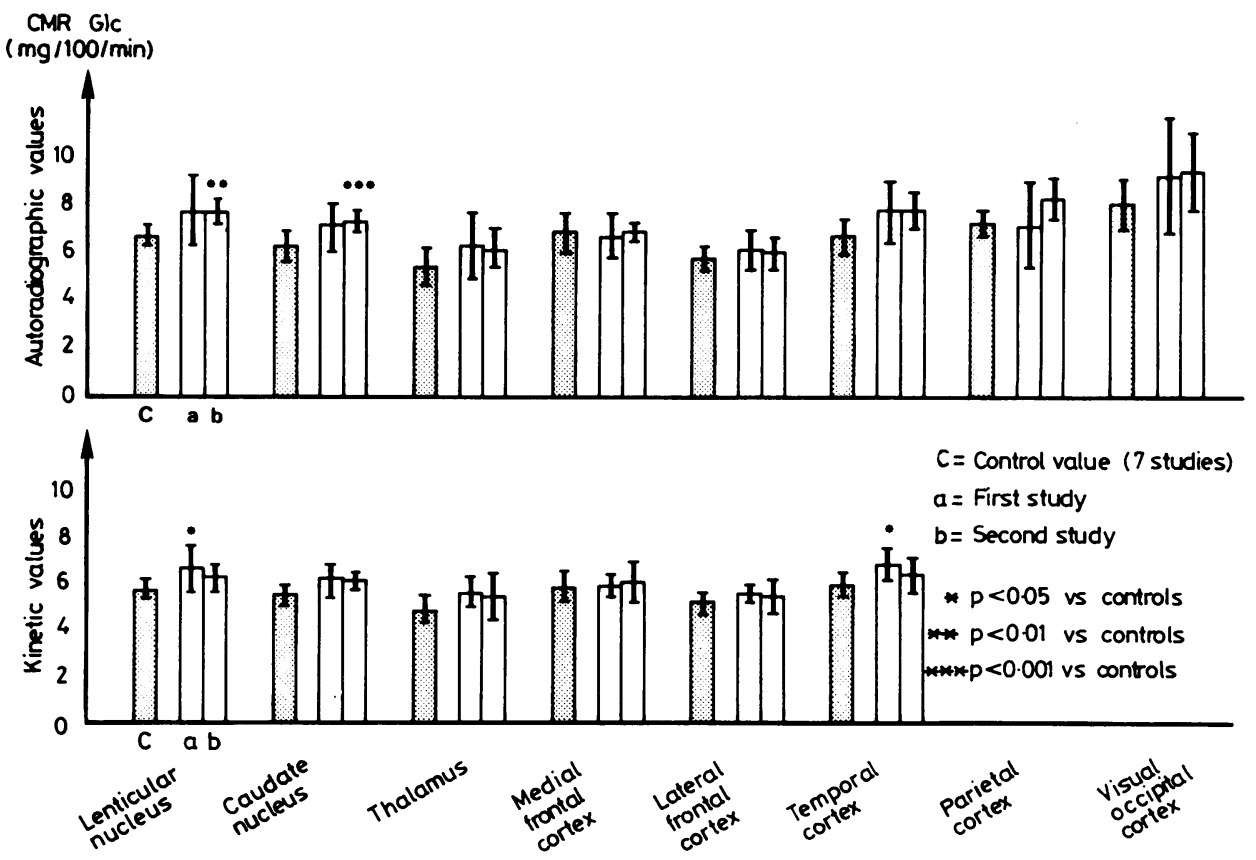

Fig. 3 Mean and one standard deviation of ICMRGlc values obtained in various cerebral structures by the in vivo autoradiographic approach (top) and the kinetic method (bottom) in seven controls $C$, shaded boxes) and Parkinson's disease patients in the untreated (a, first study) and treated ( $b$, second study) conditions.

caudate and lenticular nuclei were significantly higher than controls. Although these discrepancies would appear to weaken the pathophysiological relevance of such findings, the lenticular and caudate values in both the treated and the untreated conditions and using both methods, were consistently higher than controls values, albeit not always significantly so (table 4 , fig 3 ). Perhaps studying larger series of Parkinson's disease patients and using a PET device of improved spatial resolution (to minimise the partial volume effect ${ }^{26}$ ) would confirm this impression of higher metabolism in the basal ganglia of Parkinson's disease patients. It must be stressed, however, that the basal ganglia ICMRGlc was not influenced by levodopa (table 3 ), and hence that the relationship between the above changes and the clinical condition appears at best marginal.

The main goal of the present study was to investigate the effects of levodopa on ICMRGlc in our patient sample. Despite dramatic clinical improvement afforded by reinstitution of therapy, no alteration in ICMRGlc was found in any of the brain structures analysed. Having used both the autoradiographic method and the presumably more reliable kinetic method ${ }^{17}$ further supports this negative finding.
Although no other study of 1CMRGlc in Parkinson's disease patients has been published yet, our negative findings are consonant with previously published studies of rCBF in Parkinson's disease patients. In 26 Parkinson's disease patients, two weeks of levodopa therapy induced no modification of rCBF $\left({ }^{133} \mathrm{Xe}\right.$ inhalation technique).$^{10} \mathrm{In}$ another study, using the same technique, a moderate but significant diffuse reduction in $\mathrm{rCBF}$ in 60 Parkinson's disease patients (both treated and untreated) compared to aged-matched controls was reported, but this reduction was not seen in the young, earlyonset Parkinson's disease patients subgroup." Recently, a similar reduction in $\mathrm{rCBF}$ (preferentially affecting the frontal cortex) was reported, but again early-onset Parkinson's disease patients were spared. $^{12}$ If the normal couple between CBF and energy metabolism ${ }^{19}$ is maintained in Parkinson's disease, the above studies would indicate that cortical metabolism is unaffected in early-onset Parkinson's disease patients, and hence would agree with our findings, but that, on the other hand, late onset Parkinson's disease is associated with diffuse or preferentially frontal hypo-metabolism.

In a semiquantitative study of relative cerebral perfusion and oxygen metabolism using oxygen-15 and 2-dimensional scintigrams, Lenzi et al ${ }^{13}$ found a 
decreased metabolism in the parietal lobe contralateral to the affected limbs in several patients with hemi-Parkinsonism. Although we did not study similar cases, our data suggest preserved ICMRGlc in the parietal cortex in bilateral Parkinson's disease.

Our essentially negative findings in human Parkinson's disease are also consonant with one quantitative autoradiographic study, showing no asymmetry of ${ }^{14} \mathrm{CDG}$ retention in the brain of rats after unilateral 6-hydroxy-dopamine (6-OHDA) destruction of the substantia nigra. ${ }^{6}$ Likewise, in the same rat model of unilateral Parkinson's disease, no alteration in $\mathrm{rCBF}^{27}$ or cytochrome oxydase redox shifts $^{28}$ were observed in any part of the brain. However, four more detailed studies of ${ }^{14} \mathrm{CDG}$ uptake in brain autoradiograms of rats with unilateral 6-OHDA lesions of the substantia nigra or of the ventral tegmental area provided fairly consistent results suggesting a small (3-9\%) reduction in CMRGlc in the ipsilateral striatum, and a larger CMRGlc increase in the ipsilateral pallidum (10$40 \%$ ) and lateral habenular nucleus ( $8-24 \%$ ), while smaller changes were inconsistently seen in other structures. $^{5-9}$ That these alterations in ICMRGlc resulted from lesions of the DA systems was shown by their absence in 6-OHDA lesioned rats treated with the DA agonist apomorphine. ${ }^{57}$ (Only after extensive 6-OHDA or electrolytic lesions of the mesencephalic tegmentum or lateral hypothalamus were marked decreases in ipsilateral frontal cortex ICMRGlc, unaltered by treatment with apomorphine, observed. ${ }^{4}$ ) To the best of our knowledge, there has been no study of the acute effects of levodopa on ICMRGlc in rats with unilateral 6-OHDA lesions of the substantia nigra. When administered to normal rats, levodopa-induced changes in the relative pattern of ${ }^{14} \mathrm{CDG}$ distribution in brain that were difficult to interpret. ${ }^{29}$ Apomorphine, however, when given to normal rats, increased ICMRGlc in the caudate nucleus in a dose-dependent manner - an effect opposite to that of 6-OHDA nigro-striatal lesion-and decreased ICMRGlc in the anterior cingulate cortex. ${ }^{30}$ Taken together, therefore, the above animal studies suggested that ascending dopaminergic systems have presumably direct effects chiefly on striatal and lateral habenula glucose utilisation (stimulation and deprivation of dopaminergic transmission increasing and decreasing lCMRGlc, respectively) and presumably indirect metabolic effects on the pallidum (most likely though the striato-pallidal projections). These metabolic effects, however, remain relatively small.

No such changes were found in the present PET study of Parkinson's disease patients. This discrepancy may result from several differences between our human study and the above animal experiments. First, the relevance of the rat model of Parkinson's disease to the real human disease may be questioned, if only because of extensive biochemical defects other than those affecting the nigrostriatal dopaminergic systems. ${ }^{31}$ Second, the lCMRGlc changes reported in rats were either too small (for example, in striatum) or too circumscribed (for example, in pallidum and lateral habenula) to be reliably detected in humans by our PET detection device, even if they did occur. ${ }^{26}$ Third, as yet another effect of partial volume averaging, any putaminal decrease in CMRGlc would have been obscured, in our single "lenticular" ROI (see Methods), by the expected pallidal CMRGlc increase. Fourth, the levodopa therapy withdrawal and reinstitution intervals in our study (48 and $22 \mathrm{hrs}$, respectively) may have been too short to induce maximal effects on the dopaminergic content at terminal sites, and, in turn, on ICMRGlc. ${ }^{89}$ Irrespective of the magnitude of changes in dopaminergic content, the clinical effects were nevertheless quite dramatic but did not result in any detectable alteration in ICMRGlc.

Despite the above-mentioned problems and additional limitations such as small patient sample and potential repositioning inaccuracies, the present study failed to detect changes in lCMRGlc that could be attributable to the clinical features of early-onset Parkinson's disease, or to modifications of the latter by levodopa therapy. This suggests that the marked functional alterations that must underlie the clinical symptoms of Parkinson's disease have metabolic counterparts that are either too small in magnitude or too localised, or both, to be reliably demonstrated by most current PET devices. However, it remains to be seen whether or not abnormalities in ICMRGlc occur in patients with lateonset or unilateral Parkinson's disease, and whether positron tomographs of improved spatial resolution are capable of detecting more localised changes in the energy metabolism of the Parkinsonian brain.

Note added in proof: Since this study was completed, two quantitative PET studies of cerebral metabolism in Parkinson's disease patients have been published in abstract form. Kuhl et al (J. Nucl. Med., 1983;24:21) found no alteration of 1CMRGlc in nine treated and two untreated patients. Leenders et al (J. Cereb. Blood Flow Metabol., 1983;3,Suppl.1:S488-9) found the regional cerebral oxygen consumption ( $\mathrm{rCMRO}_{2}$ ) essentially unaltered in the untreated state, save for relatively increased values in the affected basal ganglia of patients with unilateral disease; acute levodopa challenge increased the overall $\mathrm{rCMRO}_{2}$, although this was presumably a methodological artifact, while the basal ganglia $\mathrm{rCMRO}_{2}$ was found increased after several weeks of treatment. 


\section{References}

' Sokoloff L. Relationships among local functional activity, energy metabolism and blood flow in central nervous system. Fed Proc 1981;40:2311-6.

${ }^{2}$ Hornykiewicz O. Brain dopamine in Parkinson's disease and other neurological disturbances. In: Horn AS, Korf J, Westerink BHC, eds, The Neurobiology of Dopamine. New York: Academic Press, 1979:63343.

${ }^{3}$ Scatton B, Rouquier L, Javoy-Agid F, Agid Y. Dopamine deficiency in the cerebral cortex in Parkinson disease. Neurology (NY) 1982;32:1039-40.

${ }^{4}$ Schwartz WJ, Sharp FR, Gunn RH, Evants EV. Lesions of ascending dopaminergic pathways decrease forebrain glucose uptake. Nature 1976;261:261-7.

${ }^{5}$ Schwartz WJ. A role for the dopaminergic nigrostriatal bundle in the pathogenesis of altered brain glucose consumption after lateral hypothalamic lesion. Evidence using the ${ }^{14} \mathrm{C}$-labeled deoxyglucose technique. Brain Res 1978;158: 129-47.

- Sagar JM, Snodgrass SR. Effects of substantia nigra lesions of forebrain 2-Deoxyglucose retention in the rat. Brain Res 1980;185:335-48.

${ }^{7}$ Kozlowski MR, Marshall JF. Plasticity of ${ }^{14} \mathrm{C}$-2-deoxy $\mathrm{D}$-glucose incorporation into neostriatum and related structures in response to dopamine neurone damage and apomorphine replacement. Brain Res 1980;197: 167-83.

${ }^{8}$ Wooten GF, Collins RC. Metabolic effects of unilateral lesion of the substantia nigra. $J$ Neurosci 1981; 1:3:285-91.

${ }^{9}$ Kozlowski MR, Marshall JF. Recovery of function and Basal ganglia ${ }^{14} \mathrm{C}$-2-deoxyglucose uptake after nigrostriatal injury. Brain Res 1983;259:237-48.

${ }^{10}$ Melamed E, Lavy S, Cooper G, Bentin S. Regional cerebral blood flow in Parkinsonism. J Neurol Sci 1978;38:391-397.

"Lavy S, Melamed E, Cooper G, Bentin S. Regional Cerebral Blood flow in patients with Parkinson's disease. Arch Neurol. 1979;36:344-8.

12 Bes A, Guell A, Fabre N, Dupin P, Victor G, Geraud G. Cerebral blood flow studied with xenon-133 inhalation technique in parkonsonism: loss of hyperfrontal pattern. J CBF Metabol 1983;3:33-37.

${ }^{13}$ Lenzi GT, Jones T, Reid JL, Moss S. Regional impairment of cerebral oxidative metabolism in Parkinson's disease. J Neurol Neurosurg Psychiatry 1979;22:5962.

${ }^{14}$ Lhermitte F, Agid Y, Signoret JL. Onset and end-ofdose levodopa induced dyskinesias. Arch Neurol 1978; 35:261-3.

${ }^{15}$ Reivich M, Kuhl D, Wolf A, et al. The $\left({ }^{18} \mathrm{~F}\right)$ fluorodeoxyglucose method for the measurement of local cerebral glucose utilization in man. Circ Res 1979;44:127-37.

${ }^{16}$ Phelps ME, Huang SC, Hoffman EJ, et al. Tomographic measurement of local cerebral glucose metabolic rate in humans with (F-18) 2-fluoro-3-deoxy-D-glucose. Validation of method. Ann Neurol 1979;6:371-88.

${ }^{17}$ Huang SC, Phelps ME, Hoffman EJ, et al. Non-invasive determination of local cerebral metabolic rate of glucose in man. Am J Physiol 1980;238:E69-E82.

${ }_{18}$ Phelps ME, Hoffman EJ, Huang SC, et al. ECAT: A new computerized tomographic imaging system for positron emitting radiopharmaceuticals. $J$ Nucl Med 1978; 19:635-7.

${ }^{19}$ Baron JC, Lebrun-Grandié P, Collard P, et al. Noninvasive measurement of blood flow, oxygen consumption and glucose utilization in the same brain regions in man by positron emission tomography. $\mathrm{J} \mathrm{Nucl}$ Med 1982;23:391-9.

${ }^{20}$ Hawkins RA, Phelps ME, Huang SL, Kuhl DE. Effect of ischemia on quantification of local cerebral glucose metabolic rate in man.J Cerebral Blood Flow Metabol 1981;1:37-51.

${ }^{21}$ Sokoloff L, Reivich M, Kennedy C, et al. The ${ }^{14} \mathrm{C}-$ deoxyglucose method for the measurement of local cerebral glucose utilization: theory, procedure and normal values in the conscious and anesthetized albino rat. $J$ Neurochem 1977;28:897-916.

${ }^{22}$ Reivich M, Alavi A, Wolf A, Greenberg JH, et al. Use of 2-Deoxy-D(1- $\left.{ }^{11} C\right)$ Glucose for the determination of local cerebral glucose metabolism in humans: Variation within and between subjects. $J$ Cerebral Blood Flow Metabol 1982;2:307-19.

${ }^{23}$ Bustany P, Sargent T, Saudubray JM, Henry JF, Comar $D$ regional brain uptake and protein incorporation of "C-L-methionine studied in vivo with PET. J Cerebral Blood Flow Metabol 1981, 1, Suppl. 1:S17-S18.

${ }^{24}$ Lebrun-grandie P, Baron JC, Soussaline F, Loc'h C, Sastre J, Bousser MG. The coupling between regional blood flow and oxygen utilization in the normal human brain; a study with positron tomography and oxygen 15. Arch Neurol 1983;40:230-6.

${ }^{25}$ Mazziotta JC, Phelps ME, Miller J, Kuhl DE. Tomographic mapping of human cerebral metabolism: normal unstimulated state. Neurology (NY) 1981;31:503-16.

${ }^{26}$ Maxxiotta JC, Phelps ME, Plummer D, Kuhl DE. Quantitation in positron emission computed tomography: physical anatomical effects. J Comput Assist Tomogr 1981;5:734-43.

${ }^{27}$ Lindvall $O$, Ingvar M, Steneir V. Effects of metamphetamine on blood flow in the caudate putamen after lesions of the ingrostriatal dopaminergic bundle in the rate. Brain Res 1981;211:216.

${ }^{28}$ Harik SI, La Manna JC, Snyder S, Wetherbee JR, Rosenthal M. Abnormalities of cerebral oxidative metabolism in animal models of Parkinson disease. Neurology (NY) 1982;32:382-9.

${ }^{29}$ Warner LL, Brown LL, Wolfson LI. L-Dopa produces regional changes in glucose utilization which form discrete anatomic patterns in motor nuclei and the hypothalamus of rats. Exp Neurol 1982;78:591-601.

${ }^{30}$ McCullogh, Savaki HE, McCullogh M, Jehle J, Sokoloff L. The distribution of alterations in energy metabolism in the rat brain produced by apomorphine. Brain Res 1982; 243:67-80.

31 Javoy-Agid F, Ruberg M, Taquet H, et al. . Biochemical neuropathology of Parkinson's disease. Advances in Neurology, Vol. 40, RG Hassler and JF Christ eds, New York: Raven Press, 1983;189-98.

${ }^{32}$ Hoehn MM, Yahr MD. Parkinsonism: onset, progression, and mortality. Neurology (Minneap) 1967; 17:427. 